\title{
Hydrogen adsorption on nano-structured platinum electrodes
}

\author{
Oscar Diaz-Morales, $\uparrow$ Thomas J. P. Hersbach, iD $\uparrow$ Cansin Badan, \\ Amanda C. Garcia and Marc T. M. Koper (DD *
}

Received 8th March 2018, Accepted 27th March 2018

DOI: $10.1039 / c 8 f d 00062 j$

The "hydrogen region" of platinum is a powerful tool to structurally characterize nanostructured platinum electrodes. In recent years, the understanding of this hydrogen region has improved considerably: on $\mathrm{Pt}(111)$ sites, there is indeed only hydrogen adsorption, while on step sites, the hydrogen region involves the replacement of adsorbed hydrogen by adsorbed hydroxyl which interacts with co-adsorbed cations. However, the hydrogen region features an enigmatic and less well-understood "third hydrogen peak", which develops on oxidatively roughened platinum electrodes as well as on platinum electrodes with a high (110) step density that have been subjected to a high concentration of hydrogen. In this paper, we present evidence that the peak involves surface-adsorbed hydrogen (instead of subsurface hydrogen) on a locally "reconstructed" (110)-type surface site. This site is unstable when the hydrogen is oxidatively removed. The cation sensitivity of the third hydrogen peak appears different from other step-related peaks, suggesting that the chemistry involved may still be subtly different from the other features in the hydrogen region.

\section{Introduction}

Nano-structured electrocatalysts are important for many electrochemical processes occurring in fuel cells, electrolysers, electroanalytical devices and other electrochemically catalyzed surface reactions. ${ }^{1}$ Since platinum is by far the most used electrocatalyst material, understanding and controlling its reactivity in relation to its nanoscale structure is a central challenge in electrocatalysis.

The relation between the atomic and nanoscale structure of platinum and its reactivity can be studied in various ways. The structure sensitivity of many platinum-catalyzed electrochemical reactions has been studied in great detail by performing experiments with single-crystal surfaces of platinum. ${ }^{2,3}$ Much of this knowledge can be translated into the reactivity of well-defined "shape-controlled" nanoparticles, whose reactivity can to a large extent be deconvoluted into 
contributions of different facets and active sites. ${ }^{3,4}$ Another area of interest is the reactivity of individual nano-sized platinum objects such as a single platinum nanoparticle or a single platinum nano- or (ultra)micro-electrode. ${ }^{5}$

In order to draw meaningful conclusions about the reactivity of nanoscale platinum, it is important to have a simple and reliable technique to check and verify the structure and cleanliness of the nano-sized or nano-structured platinum electrode. This characterization is typically performed by recording a blank voltammogram of the platinum electrode in acidic solution. For instance, the electrochemical signal of the adsorption of hydrogen of platinum is highly sensitive to its structure and cleanliness, and is generally used to draw conclusions about the electrochemically active surface area and its structure. As a consequence, the electrochemical adsorption of hydrogen on platinum electrodes is one of the most extensively studied topics in surface electrochemistry. The blank cyclic voltammogram of polycrystalline platinum (in both acidic and alkaline electrolytes) shows a region between 0.05 and $0.4 \mathrm{~V}_{\mathrm{RHE}}$ with several adsorption peaks, a potential window typically referred to as the "hydrogen region". There is a good understanding of the relation of these peaks to their single-crystal counterparts, meaning that the prominence of certain peaks contains quantitative information about the dominant surface facets and surface sites on a given nanostructured or polycrystalline platinum surface. ${ }^{1-4}$ Blank cyclic voltammetry has also been extensively used to characterize platinum micro- and nano-electrodes to characterize their surface structure and cleanliness. ${ }^{5-7}$

However, the chemical interpretation of the peaks is still under discussion. In addition, there is a peak that is often observed on nanostructured and polycrystalline platinum that only appears in the anodic part of the blank voltammogram, at a potential between two peaks attributed to hydrogen adsorbed on (110) and (100) step sites, the reason why it is often referred to as the "third hydrogen peak". Several papers have studied the nature of this peak. ${ }^{8-15}$ The peak appears after the platinum electrode has been oxidized at sufficiently high potential or when the platinum electrode has been contact with a sufficiently high hydrogen $\left(\mathrm{H}_{2}\right)$ concentration, and the oxidation of the species involved in the peak is slow and irreversible compared to the other peaks in the hydrogen region. There appears to be a lack of consensus in the literature as to whether the peak involves the formation of some kind of subsurface hydrogen, or whether it is purely surface confined. Sumino and Shibata ${ }^{11}$ and Frelink et al. ${ }^{13}$ suggested the formation of subsurface molecular hydrogen, on the basis of arguments that we will explain later in this paper, whereas Gomez and Clavilier $^{12}$ used extensive single-crystal measurements to argue that the peak is related to hydrogen desorption from reconstructed two-dimensional (110)-(2 $\times$ 1) domains, suggesting that the chemistry of the third hydrogen peak is surface confined.

In this paper, we will briefly summarize our current understanding of the processes taking place in the hydrogen region of nanostructured platinum electrodes, and we will present new electrochemical and spectroscopic results regarding the "third hydrogen peak". We will discuss the possible structural and chemical nature of the peak in relation to the contemporary understanding of the nature of the other peaks in the hydrogen region. 


\section{Experimental}

Electrochemical experiments were performed at room temperature with a potentiostat (Bio-Logic SP-300) using a large area Pt counter electrode. For acidic and alkaline electrolytes, a reversible hydrogen electrode (RHE) and a commercial and self-contained RHE (Gaskatel, Hydroflex®) built in PTFE were chosen as a reference electrode, respectively. Platinum wires (Mateck, 99.99\%, $0.1 \mathrm{~mm}$ diameter), a bead-type poly-oriented platinum sphere, and bead-type electrodes of $\operatorname{Pt}(100)$, $\operatorname{Pt}(110), \operatorname{Pt}(111)$ and $\mathrm{Pt}(553)$ orientation, prepared according to the Clavilier method, ${ }^{16}$ were used as working electrodes. Prior to each experiment, the single crystal electrode was annealed in a butane flame and cooled down to room temperature in a $\mathrm{H}_{2}+\mathrm{Ar}$ (Linde, purity grade 6.0) atmosphere. Subsequently, it was transferred to the cell under the protection of a droplet of deoxygenated water. For the polycrystalline Pt wires, the working area was defined by immersing ca. $1 \mathrm{~mm}$ of wire using a micrometer screw.

All glassware used in the experiments was rigorously cleaned by boiling in concentrated $\mathrm{H}_{2} \mathrm{SO}_{4}$ and was successively boiled five times in Milli-Q water (resistivity $>18.2 \mathrm{M} \Omega \mathrm{cm}$, TOC $<5 \mathrm{ppb}$ ), which is also used for preparing electrolyte solutions. For all the experiments, dissolved $\mathrm{O}_{2}$ in solutions was removed prior to measurements by bubbling argon (Linde, purity grade 6.0). Throughout the measurements a blanket of Ar was kept flowing over the solution.

The electrochemical experiments with $0.1 \mathrm{M} \mathrm{H}_{2} \mathrm{SO}_{4}$ (Merck, Ultrapur®), ortho-phosphoric acid (Merck, Suprapur ${ }^{\circledR}$ ), $\mathrm{HClO}_{4}$ (Merck, Suprapur®), $\mathrm{KClO}_{4}$ (Merck, 99.99\%) were conducted in a two-compartment and three-electrode cell made of glass. When $0.1 \mathrm{M} \mathrm{NaOH}$ (Fluka TraceSelect ${ }^{\circledR}$ for trace analysis, 30\% solution in $\mathrm{H}_{2} \mathrm{O}$ ) is chosen as the electrolyte, we used a single compartment and three-electrode cell made of fluorinated ethylene propylene (FEP) for the electrochemical treatments. After the anodic-cathodic treatments, a blank voltammogram of the electrode was subsequently characterized in the same solution to observe the changes in the "third hydrogen peak". All the potentials in this study are referred the reversible hydrogen electrode (RHE) scale, unless otherwise stated. Ohmic drop compensation was carried out in situ by determining the cell resistance through impedance spectroscopy before the experiment. To avoid oscillations in the potentiostat due to high cell resistances (on the order of $12 \mathrm{k} \Omega$ for $1 \mathrm{mM} \mathrm{HClO}_{4}$ ), $85 \%$ of the cell resistance was accounted for in situ, while the remaining cell resistance was compensated for manually after the experiment.

Fourier-transform infrared (FTIR) experiments were performed using a Bruker Vertex 80V IR spectrometer equipped with a liquid nitrogen cooled detector, in a three electrode spectro-electrochemical cell with a $\mathrm{CaF}_{2}$ prism attached to the bottom of the cell. Details concerning the cell and the setup are described in the literature. ${ }^{17}$ FTIR spectra were obtained in the wavenumber range between $4500 \mathrm{~cm}^{-1}$ to $1000 \mathrm{~cm}^{-1}$. Spectra were collected in $0.05 \mathrm{~V}$ steps from $0.05 \mathrm{~V}$ to $0.25 \mathrm{~V} v s$. RHE. They were computed from the average of 400 interferograms with the spectral resolution set to $8 \mathrm{~cm}^{-1}$. Spectra are presented as absorbance, according to $A=-\log \left(R / R_{0}\right)$, where $R$ and $R_{0}$ are the reflectance corresponding to the single beam spectra obtained at the sample and reference potentials, respectively. 


\section{Current understanding of the "hydrogen region"}

Fig. 1 shows a blank cyclic voltammogram of a polycrystalline platinum electrode in sulfuric acid solution, highlighting the potential window below $0.7 \mathrm{~V}_{\mathrm{RHE}}$. The Figure indicates two main regions of the voltammogram: the "hydrogen region" below $c a$. $0.4 \mathrm{~V}_{\mathrm{RHE}}$ in which hydrogen adsorbs and desorbs reversibly onto various sites of the platinum surfaces, and the "double layer region" between $c a$. 0.4 and $0.7 \mathrm{~V}_{\mathrm{RHE}}$ in which the Pt/sulfuric acid interface is supposedly ideally polarizable. Above $0.7 \mathrm{~V}$ there is the "oxide region" in which an oxide is formed onto the Pt surface, which is irreversibly reduced in the subsequent negative-going scan. We will not consider the oxide region here. In the hydrogen region, the different peaks correspond to signals from specific sites. The (110) and (100) step sites at ca. $0.125 \mathrm{~V}$ and $0.27 \mathrm{~V}$, resp., indicated in the Figure by the symbols $\mathrm{H}_{\mathrm{I}}$ and $\mathrm{H}_{\mathrm{II}}$, are the most conspicuous. In addition, the (111) terrace sites give a broad reversible adsorption-desorption wave between 0.05 and $0.35 \mathrm{~V}_{\mathrm{RHE}}$ (see also Fig. 7 below). The (100) terrace sites are not indicated in Fig. 1 but typically give rise to a "foot" in the hydrogen region above $0.35 \mathrm{~V}_{\mathrm{RHE}}$. Sulfate adsorption on $\mathrm{Pt}(111)$ terrace sites also gives a signal at potentials above $0.35 \mathrm{~V}_{\mathrm{RHE}}$ (see also Fig. 7 further below), meaning that in sulfuric acid solution, platinum is covered by adsorbed (bi-) sulfate in the double layer region. The "third hydrogen peak" $\mathrm{H}_{\mathrm{III}}$ is situated in between $\mathrm{H}_{\mathrm{I}}$ and $\mathrm{H}_{\mathrm{II}}$, but it is only observed in the positive-going scan.

The classic interpretation of the hydrogen region is that the peaks correspond to proton discharge into adsorbed hydrogen in the negative-going scan, and vice versa in the positive-going scan, on the various sites discussed in the previous paragraph and as indicated in the Figure:

$$
\mathrm{H}^{+}+\mathrm{e}^{-}+{ }_{h k l} \leftrightarrows \mathrm{H}_{\mathrm{ads}, h k l}
$$

with $*_{h k l}$ indicating a free site on the Pt surface with $h k l$ Miller indices. For the $\mathrm{Pt}(111)$ terrace sites, this interpretation is consistent with the experimental data. However, for the (110) and (100) step sites, the pH dependence of the peak is not consistent with eqn (1), as the peaks shift to considerably higher potential (on the

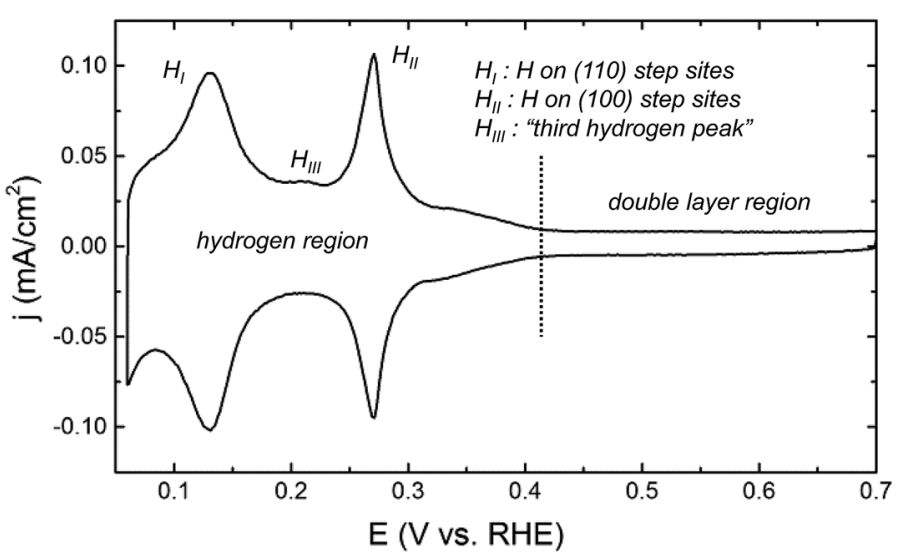

Fig. 1 Blank voltammogram of a polycrystalline platinum electrode in $0.5 \mathrm{M} \mathrm{H}_{2} \mathrm{SO}_{4}$. Scan rate $50 \mathrm{mV} \mathrm{s}^{-1}$. 
RHE scale) in alkaline media. ${ }^{18}$ We recently presented detailed experimental and computational evidence that this non-Nerstian $\mathrm{pH}$ dependence of the $\mathrm{H}_{\mathrm{I}}$ and $\mathrm{H}_{\mathrm{II}}$ peaks is explained well by a model in which step-adsorbed $\mathrm{H}$ is replaced by stepadsorbed $\mathrm{OH}$, where the stability of step-adsorbed $\mathrm{OH}$ is influenced by the nature and concentration of the cation in solution (hence explaining the apparent $\mathrm{pH}$ dependence). ${ }^{19,20}$ This implies that at potentials positive of the $\mathrm{H}_{\mathrm{I}}$ and $\mathrm{H}_{\mathrm{II}}$ peaks, $\mathrm{OH}$ is adsorbed in the step sites of platinum. Therefore, the classic division between the "hydrogen region" and the "double layer region" of nanostructured and polycrystalline platinum is not chemically accurate; only the $\operatorname{Pt}(111)$ surface has a true hydrogen region and a true double-layer region (in perchloric acid). ${ }^{21}$ This "new" understanding of the "hydrogen region" of Pt also sheds new light on, and raises new questions regarding, the nature of the $\mathrm{H}_{\mathrm{III}}$ peak.

\section{Results and discussion}

In this section, we will first illustrate some of the basic conditions under which the "third hydrogen peak" is observed. Next, we will present some new experiments aiming to address the question if this peak involves surface-adsorbed hydrogen or subsurface hydrogen.

Fig. 2 illustrates how the "third hydrogen peak" becomes more pronounced if the anodic "pretreatment" becomes more oxidizing. Specifically, the electrode was brought into meniscus configuration at $0.08 \mathrm{~V}$, after which a potential between 0.6 and $1.5 \mathrm{~V}$ was applied for 130 seconds. Next, the potential was stepped back to $0.08 \mathrm{~V}$ and the potential was held for 120 seconds, after which

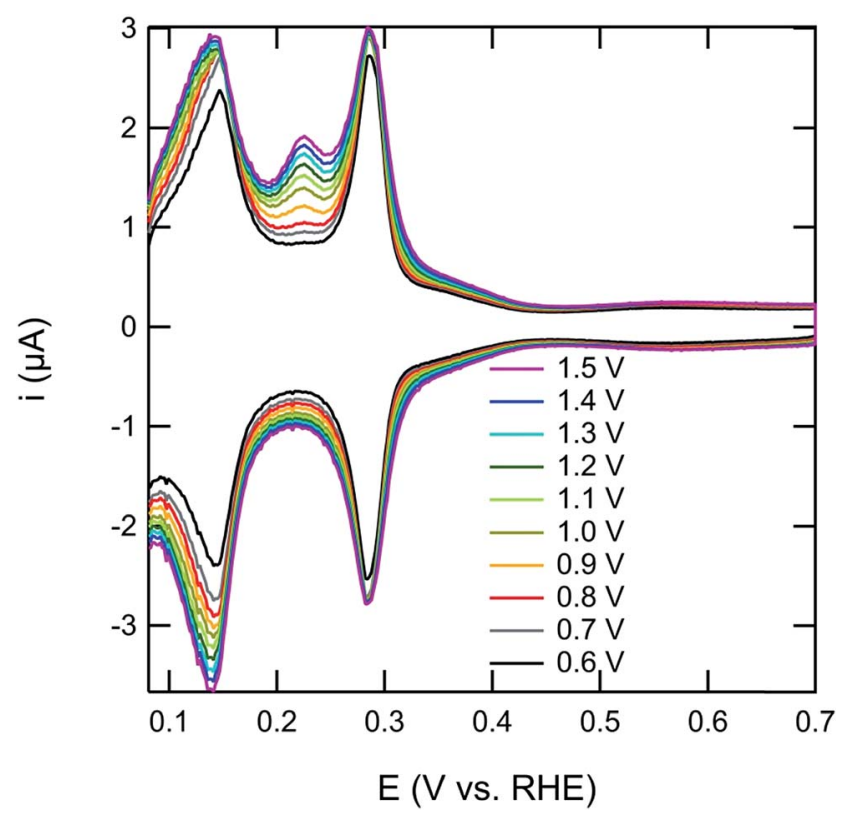

Fig. 2 Development of third hydrogen peak on a poly-oriented platinum electrode in dependence on the potential of surface oxidation in the previous potential step (for details, see text). $0.1 \mathrm{M} \mathrm{H}_{2} \mathrm{SO}_{4} ; 50 \mathrm{mV} \mathrm{s}^{-1}$. 
four consecutive cycles between 0.08 and $0.7 \mathrm{~V}$ were acquired at $50 \mathrm{mV} \mathrm{s}^{-1}$. Fig. 2 shows the first cycle obtained, for ten different potentials of anodic pretreatment between 0.6 and $1.5 \mathrm{~V}$. The more extensive the oxidation of the platinum surface during the potential step, the higher the charge associated with $\mathrm{H}_{\mathrm{III}}$. As noted in previous papers, the anodic $\mathrm{H}_{\mathrm{III}}$ peak appears to have no cathodic counterpart. In contrast to the other hydrogen peaks, $\mathrm{H}_{\mathrm{III}}$ is kinetically irreversible. Fig. 3 shows how the peak potential of $\mathrm{H}_{\mathrm{III}}$ depends on the scan rate. The slope of this curve is ca. $15 \mathrm{mV} \mathrm{dec}^{-1}$, in good agreement with the value of $17 \mathrm{mV} \mathrm{dec}^{-1}$ observed by Sumino and Shibata. ${ }^{11}$ No such scan rate dependence is observed for the other two hydrogen peaks $\mathrm{H}_{\mathrm{I}}$ and $\mathrm{H}_{\mathrm{II}}$ : in acid media they are perfectly reversible. ${ }^{22}$

As a result of this kinetic irreversibility, the cathodic counterpart of $\mathrm{H}_{\mathrm{III}}$ is in fact "hidden" by the cathodic $\mathrm{H}_{\mathrm{I}}$ peak at $0.125 \mathrm{~V}$, corresponding to hydrogen adsorption on the (110) step sites. To demonstrate this, we performed an experiment in which the cathodic vertex potential was varied between 0.18 and $0.08 \mathrm{~V}$ (see Fig. 4). If, during the oxidation-reduction cycling of the platinum electrode, the potential is reversed at $0.18 \mathrm{~V}$, no $\mathrm{H}_{\text {III }}$ peak is observed in the subsequent positive-going scan (Fig. 4a). With decreasing cathodic vertex potential, the third hydrogen peak grows (Fig. 4a), and its current peak (with respect to the background) is plotted as a function of the vertex potential in Fig. 4b. Fig. 4b demonstrates that the species that is oxidized in the $\mathrm{H}_{\text {III }}$ peak is generated at potentials below $0.17 \mathrm{~V}$, with its charge increasing until $0.08 \mathrm{~V}$. In voltammetry, this would be a broad peak, and this explains why the peak is not visible in the voltammogram itself, as it overlaps with the (110) related $H_{I}$ peak, which has a much higher intensity.

Another important observation about the $\mathrm{H}_{\text {III }}$ peak is that it loses intensity when the platinum is cycled in a potential window in which the platinum surface

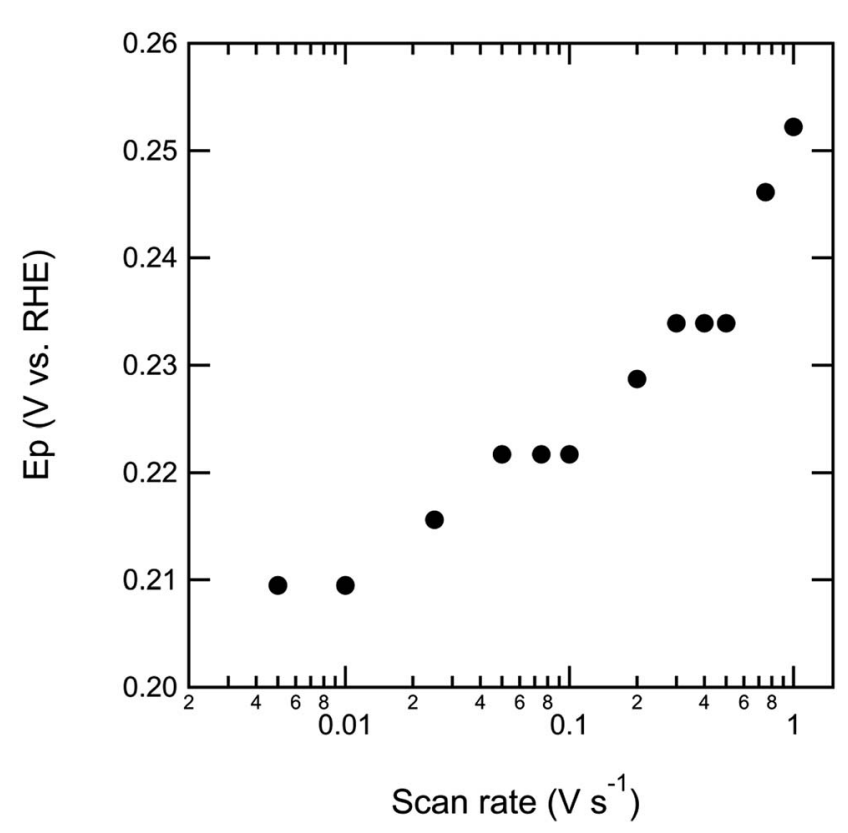

Fig. 3 Peak potential for $\mathrm{H}_{\text {III }}$ as a function of scan rate. $0.1 \mathrm{M} \mathrm{H}_{2} \mathrm{SO}_{4}$. 

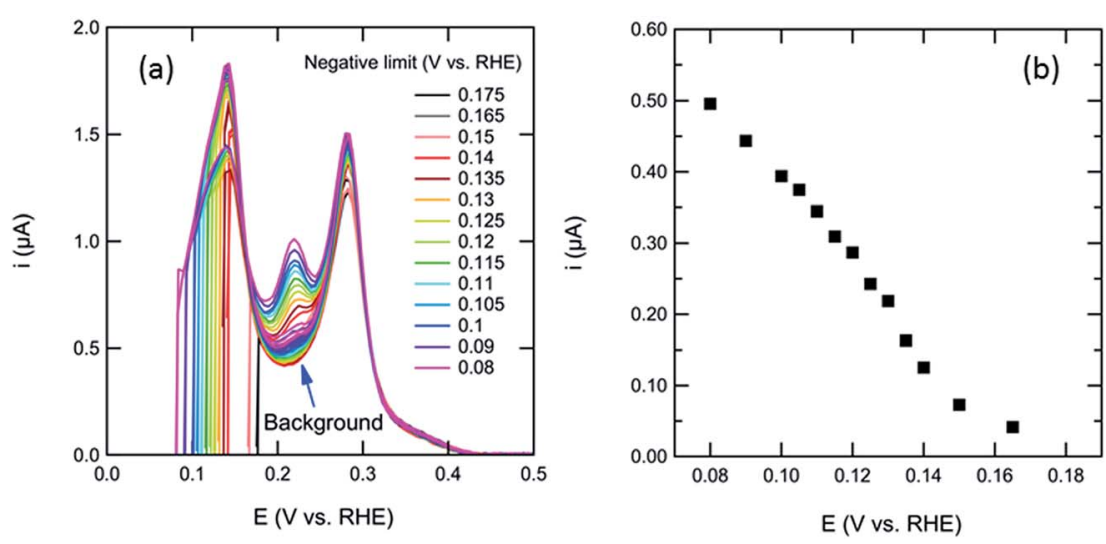

Fig. 4 (a) Development of the third hydrogen peak as a function of the negative vertex potential in the voltammogram from $0.18 \mathrm{~V}$ to $0.08 \mathrm{~V}$. (b) Current of the $\mathrm{H}_{\text {III }}$ peak (corrected for background current) as a function of the vertex potential. $0.5 \mathrm{M} \mathrm{H}_{2} \mathrm{SO}_{4} ; 50 \mathrm{mV}$ $\mathrm{s}^{-1}$.

is not oxidized. As illustrated in Fig. 5, the $\mathrm{H}_{\text {III }}$ peak disappears after several cycles, while the cathodic peak $\mathrm{H}_{\mathrm{I}}$ shows a corresponding increase in intensity. Fig. 5 displays cyclic voltammograms of $\mathrm{Pt}$ (poly) in $0.1 \mathrm{M} \mathrm{H}_{2} \mathrm{SO}_{4}$ after polarizing at $3.0 \mathrm{~V}$ ( $v s$. RHE) for $120 \mathrm{~s}$ and $0.05 \mathrm{~V}$ (vs. RHE) for $120 \mathrm{~s}$. It is clearly seen that after the first scan, the intensity of the third peak decreases significantly. Continuous scanning of the electrode in the potential window of $0.06-0.7 \mathrm{~V}$ ( $v s$. RHE) results in the disappearance of the third peak. The $\mathrm{H}_{\mathrm{I}}$ peak increases in intensity after the

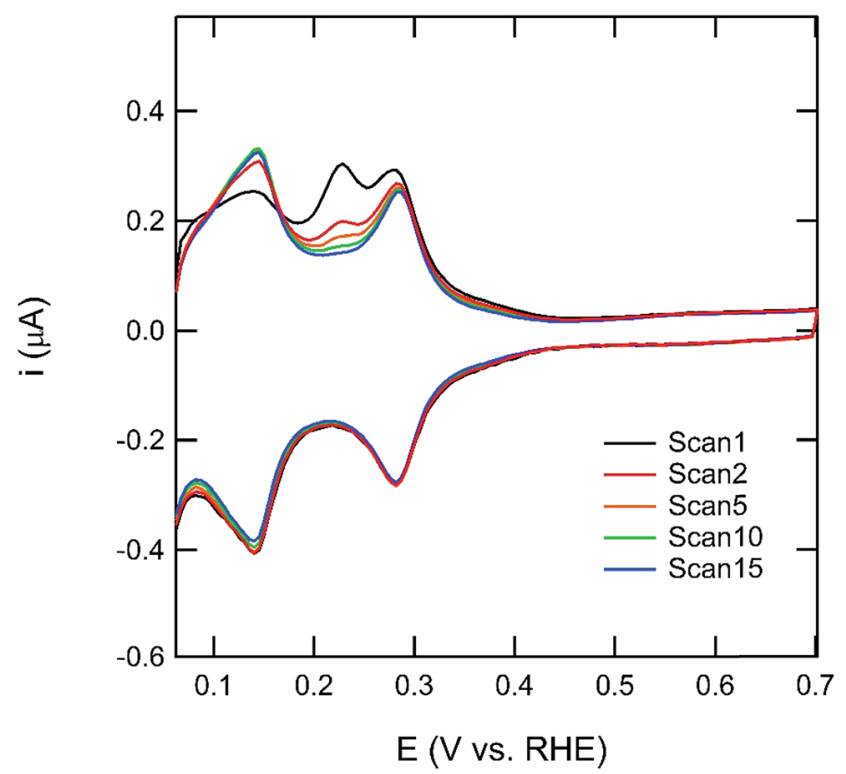

Fig. 5 Subsequent cyclic voltammograms of a polycrystalline Pt electrode showing the development of the $\mathrm{H}_{\text {III }}$ peak with number of scans $0.1 \mathrm{M} \mathrm{H}_{2} \mathrm{SO}_{4} ; 50 \mathrm{mV} \mathrm{s}^{-1}$. 
first scan. After the second scan, however, it remains stable. Sumino and Shibata have already made this observation, ${ }^{11}$ and derived that the "missing charge" in peak $\mathrm{H}_{\mathrm{I}}$ is about half that of the initial charge of $\mathrm{H}_{\mathrm{III}}$. From this observation, they concluded (together with Frelink et al. ${ }^{13}$ in a later paper), that $\mathrm{H}_{\mathrm{III}}$ involves the oxidation of subsurface molecular hydrogen $\mathrm{H}_{2}$.

To shed more light onto the "destruction" of the $\mathrm{H}_{\text {III }}$ peak, we performed the experiments shown in Fig. 6. If, after the oxidation of the platinum surface, the potential is scanned between 0.06 and $0.18 \mathrm{~V}$ (Fig. 6a), we observe a symmetric voltammogram with "missing" charge in the cathodic $\mathrm{H}_{\mathrm{I}}$ peak. The potential of $0.18 \mathrm{~V}$ is not positive enough to oxidize the species responsible for the $\mathrm{H}_{\text {III }}$ peak, and hence its corresponding reduction charge is missing in the cathodic scan from $0.18 \mathrm{~V}$ to $0.06 \mathrm{~V}$. If, on the other hand, the potential is scanned to a potential just positive of $\mathrm{H}_{\mathrm{III}}(0.25 \mathrm{~V}$ in Fig. $6 \mathrm{~b})$, there is considerably less "missing" charge in the cathodic $\mathrm{H}_{\mathrm{I}}$ peak. These observations suggest that the "site" that accommodates the species oxidized in $\mathrm{H}_{\mathrm{III}}$ is stable as long as this species is not oxidized, but the site disappears rapidly as soon as the species is oxidized.

The experiments in Fig. 5 and 6 suggest that there is strong relation between the $\mathrm{H}_{\mathrm{I}}$ and the $\mathrm{H}_{\mathrm{III}}$ peak. It appears as if during oxidation of the platinum surface, a site is generated that may accommodate the adsorbed or absorbed $\mathrm{H}_{\mathrm{III}}$ species, at the expense of hydrogen adsorbed at "regular" (110) step sites. During cycling at potentials at which the $\mathrm{H}_{\mathrm{III}}$ species is oxidized, the surface is "repaired" and the (110) step sites and the corresponding $\mathrm{H}_{\mathrm{I}}$ peak regain intensity.

The $\mathrm{H}_{\text {III }}$ peak is typically observed after cycling the platinum electrode into the oxide region. However, the $\mathrm{H}_{\text {III }}$ peak may also be observed on the first positivegoing scan after the platinum electrode has been flame-annealed in a hydrogen flame. This suggests that previous surface oxidation is not strictly necessary for the observation of the $\mathrm{H}_{\text {III }}$ peak. In accordance with these observations, Reilley et $a .^{10}$ and Gomez and Clavilier ${ }^{\mathbf{1 2}}$ showed that generating hydrogen electrochemically in situ by holding the electrode potential at a sufficiently negative potential, also generates the $\mathrm{H}_{\text {III }}$ peak in the subsequent positive-going scan (after ensuring that all generated hydrogen has left the vicinity of the electrode). Fig. 7 show that if a platinum electrode is held at $-0.4 \mathrm{~V}$ for two minutes, and the
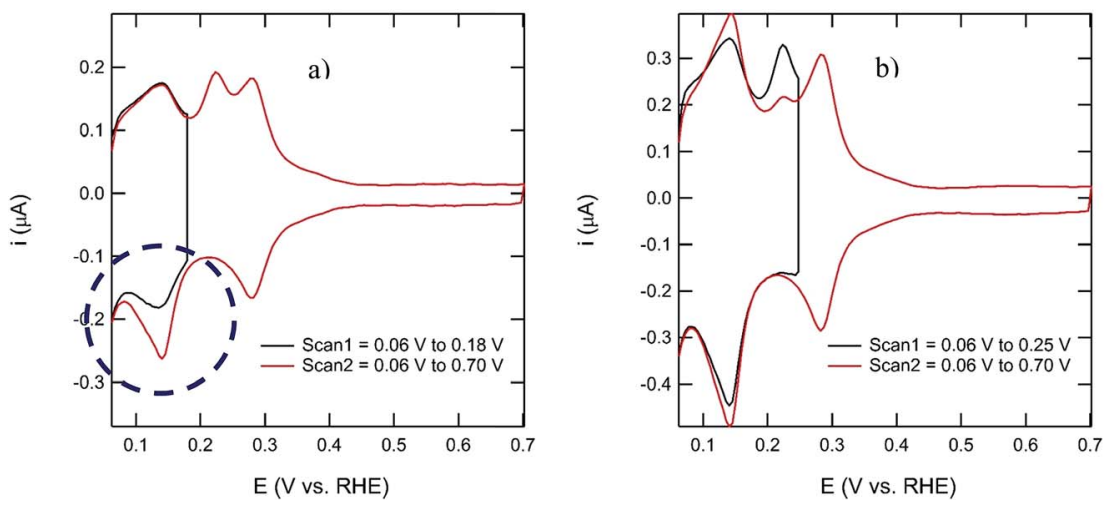

Fig. 6 Cyclic voltammograms of a polycrystalline platinum electrode in $0.1 \mathrm{M} \mathrm{H}_{2} \mathrm{SO}_{4}$. (a) First scan: $0.06-0.18 \mathrm{~V}$ (vs. RHE), second scan: 0.06-0.70 V (vs. RHE). (b) First scan: 0.06$0.25 \mathrm{~V}$ (vs. RHE), second scan: $0.06-0.70 \mathrm{~V}$ (vs. RHE). $50 \mathrm{mV} \mathrm{s}^{-1}$. 
potential is then changed to $0.06 \mathrm{~V}$ and held there long enough for $\mathrm{H}_{2}$ to diffuse away, the subsequent positive-going scan indeed shows the $\mathrm{H}_{\text {III }}$ peak. The results shown in Fig. 7 illustrate that the $\mathrm{H}_{\text {III }}$ only develops on platinum surfaces with (110) sites, such as Pt(110) and Pt(553); structurally, the step sites in Pt(553) may also be considered of the (111) type, but we will refer to them as (110) since their electrochemical signal is closer to (110). The Pt(100) and Pt(111) surface do not develop the $\mathrm{H}_{\text {III }}$ peak. Also on the single-crystal electrodes, the $\mathrm{H}_{\text {III }}$ peak quickly

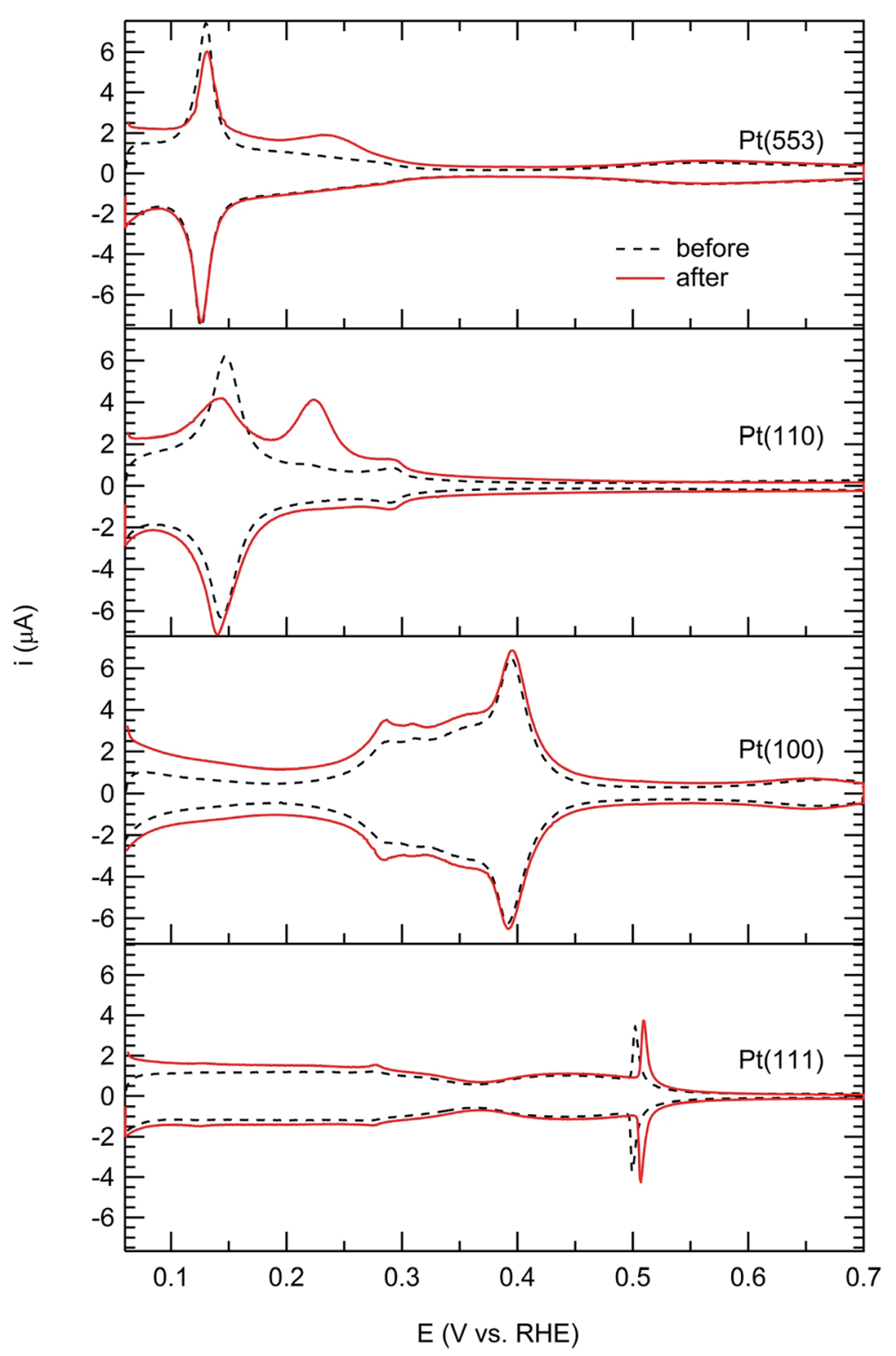

Fig. 7 Blank cyclic voltammograms of $\mathrm{Pt}(553), \mathrm{Pt}(110), \mathrm{Pt}(100)$ and $\mathrm{Pt}(111)$ in $0.1 \mathrm{M} \mathrm{H}_{2} \mathrm{SO}_{4}$ before (black dashed curve) and after (red curve) cathodic polarization at $-0.4 \mathrm{~V}_{\mathrm{RHE}}$. $\mathrm{Pt}(553)$ and $\mathrm{Pt}(110)$ clearly develop the $\mathrm{H}_{\text {III }}$ peak. $50 \mathrm{mV} \mathrm{s}^{-1}$. 
diminishes in intensity in subsequent scans. This is in good agreement with earlier results by Gomez and Clavilier, ${ }^{12}$ who showed by using a series of stepped single-crystal surfaces that the $\mathrm{H}_{\mathrm{III}}$ peak only develops on single-crystal surfaces with a sufficiently high density of (110) step sites. The charge of the $\mathrm{H}_{\text {III }}$ peak in Fig. 7 is about twice the charge lost in the $\mathrm{H}_{\mathrm{I}}$ peak, in good agreement with earlier results. ${ }^{12}$ Their single-crystal experiments suggested that the $\mathrm{H}_{\text {III }}$ peak corresponds to hydrogen oxidized from reconstructed two-dimensional $(2 \times 1)$ domains, and that a long-range order along (110)-dense rows of at least three atomic diameters is required. ${ }^{12}$ We should note that the voltammogram for $\mathrm{Pt}(110)$ shown in Fig. 7 corresponds to a disordered Pt(110)- $(1 \times 2)$ surface, rather than to a $\mathrm{Pt}(110)-(1 \times 1)$ surface, following recent results by Attard and Brew. ${ }^{23}$

Given our recently acquired new understanding of the nature of the $\mathrm{H}_{\mathrm{I}}$ and $\mathrm{H}_{\mathrm{II}}$ peaks, ${ }^{19}$ we studied the $\mathrm{pH}$ and cation dependence of the $\mathrm{H}_{\mathrm{III}}$ peak. To this end, we studied the location of the $\mathrm{H}_{\mathrm{III}}$ peak in $0.1 \mathrm{M} \mathrm{HClO}_{4}(\mathrm{pH}=1)$ and $0.001 \mathrm{M}$ $\mathrm{HClO}_{4}(\mathrm{pH}=3)$, as well as in $0.001 \mathrm{M} \mathrm{HClO}_{4}$ in the presence of different concentrations of $\mathrm{KClO}_{4}$. We decided to not perform these experiments in sulfuric acid to ensure the same conditions as in ref. 19. It is known that the observation of the $\mathrm{H}_{\text {III }}$ peak does not depend on the nature of the anion in acidic media, as we also observed the $\mathrm{H}_{\text {III }}$ peak in perchloric and phosphoric acid. However, its exact peak potential may depend on the anion in the electrolyte. ${ }^{10}$ Fig. 8 a shows the positive-going parts of voltammograms of $\mathrm{Pt}(553)$ in perchlorate media at $\mathrm{pH}=1$ and $\mathrm{pH}=3$, from 0.06 to $0.7 \mathrm{~V}$, after cathodization of the platinum electrode at $-0.4 \mathrm{~V}$ for 1 minute. The third peak is clearly observed, and we assured that it disappears in subsequent scans (not shown). From Fig. 8a, we observe that both the $\mathrm{H}_{\mathrm{I}}$ and $\mathrm{H}_{\mathrm{III}}$ peak do not shift with $\mathrm{pH}$ on the RHE scale, at least not for these two $\mathrm{pH}$ values. This confirms that both processes involve $\mathrm{a}^{+} / \mathrm{e}^{-}$reaction. In Fig. $8 \mathrm{~b}$, we observe that the $\mathrm{H}_{\mathrm{I}}$ peak is sensitive to the addition of $\mathrm{K}^{+}$: the $\mathrm{H}_{\mathrm{I}}$ peak potential shifts positively with increasing concentration of $\mathrm{K}^{+}$, at constant $\mathrm{pH}$, in good agreement with our previous results. ${ }^{19}$ However, the effect of the cation on the $\mathrm{H}_{\text {III }}$ peak is much less pronounced. We will speculate about the interpretation of this observation in the next section, but it does suggest that the exact (sub) surface chemistry corresponding to peak $\mathrm{H}_{\mathrm{III}}$ is different to that of $\mathrm{H}_{\mathrm{I}}$.

Given that peak $\mathrm{H}_{\text {III }}$ appears to correspond to a high coverage of hydrogen, ${ }^{10,12}$ we performed FTIR experiments to see if the hydrogen adsorbate or absorbate could be detected spectroscopically. To this end, a $\operatorname{Pt}(110)$ electrode in $0.1 \mathrm{M}$ $\mathrm{H}_{2} \mathrm{SO}_{4}$ was cathodized at $-0.2 \mathrm{~V}$ for 2 minutes, and subsequently characterized by FTIR spectroscopy in the external reflection mode at $0.05,0.10,0.15,0.20,0.25 \mathrm{~V}$, with an initial spectrum at $0.05 \mathrm{~V}$ serving as reference spectrum (a small instability in the thin electrolyte layer between the electrode and prism causes a slight tilting of the spectra and is the reason why the spectrum at $0.05 \mathrm{~V}$ is not flat). The spectra are plotted in Fig. 9. From $c a$. $0.15 \mathrm{~V}$, the appearance of a feature near $2000 \mathrm{~cm}^{-1}$ is observed, and its negative intensity together with some bipolar character suggests that it corresponds to a species that is being removed from the surface with more positive potential. From the comparison to previous FTIR and Raman spectroscopy experiments of electrochemical platinum-hydrogen interfaces, ${ }^{24-27}$ we attribute this feature to the $\mathrm{Pt}-\mathrm{H}$ vibration of a $\mathrm{H}$ adsorbate bound atop to a Pt surface atom. The band that we observe is some $80-100 \mathrm{~cm}^{-1}$ lower than observed by Nichols ${ }^{24}$ and Kunimatsu, ${ }^{25}$ but our observation agrees well with earlier observations by Igasawara and Ito, who also observed a weak but 

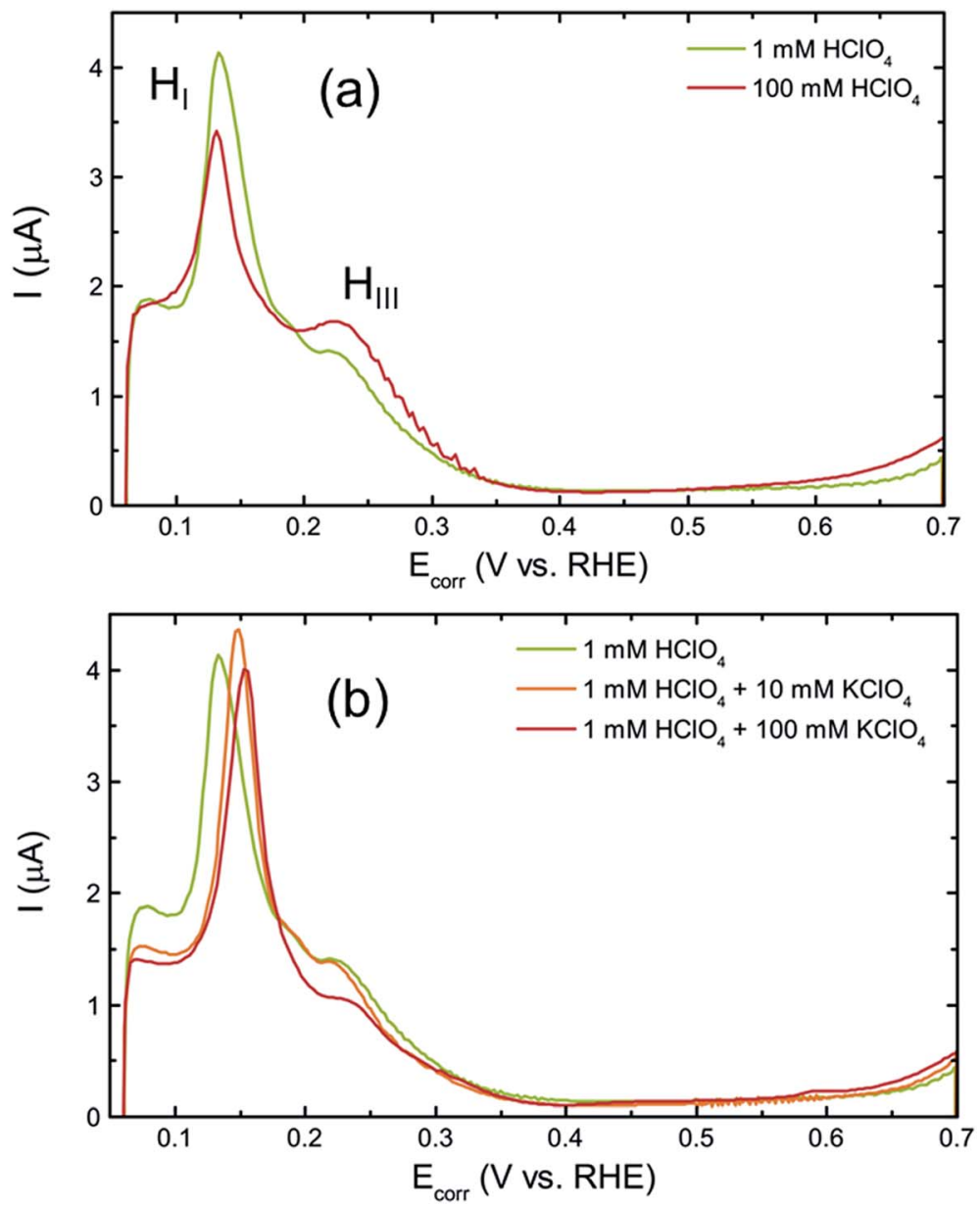

Fig. 8 Blank voltammogram of a Pt(553) electrode in perchloric acid; only the positivegoing part from $0.05 \mathrm{~V}$ to $0.7 \mathrm{~V}$ is shown, after cathodization of the electrode at $-0.4 \mathrm{~V}$ for 2 minutes. (a) Comparing $0.1 \mathrm{M}^{2}$ and $0.001 \mathrm{M} \mathrm{HClO}_{4}$; (b) the influence of adding different concentrations of $\mathrm{KClO}_{4}$ to $0.001 \mathrm{M} \mathrm{HClO}_{4}$.

reproducible peak just below $2000 \mathrm{~cm}^{-1}$ on a $\mathrm{Pt}(110)$ electrode, though the voltammetry of their electrode did not show the third peak. Significantly, this conclusion about the observation of the $\mathrm{Pt}-\mathrm{H}$ surface vibration would be inconsistent with the involvement of the subsurface hydrogen in peak $\mathrm{H}_{\mathrm{III}}$. We note that for hydrogen adsorbed in step sites at lower coverages, we expect the hydrogen to bind bridge or multifold, ${ }^{28}$ as their $\mathrm{Pt}-\mathrm{H}$ vibrations would have different frequencies and presumably lower intensities.

We note that cathodization at sufficiently negative potentials $\left(<-1 \quad \mathrm{~V}_{\mathrm{NHE}}\right)$ destabilizes the (sites related to the) $\mathrm{H}_{\mathrm{III}}$ peak. ${ }^{29}$ Under those conditions, anisotropic cathodic etching of the Pt surface occurs, which appears to remove the (110) step sites from the surface and generate (100) sites. Finally, the $\mathrm{H}_{\text {III }}$ peak can also be observed on a Pt(111) electrode after extensive cycling in perchloric acid, suggesting the formation of the corresponding (110) sites by roughening. ${ }^{30}$ 


\section{Pt(110) after cathodization}
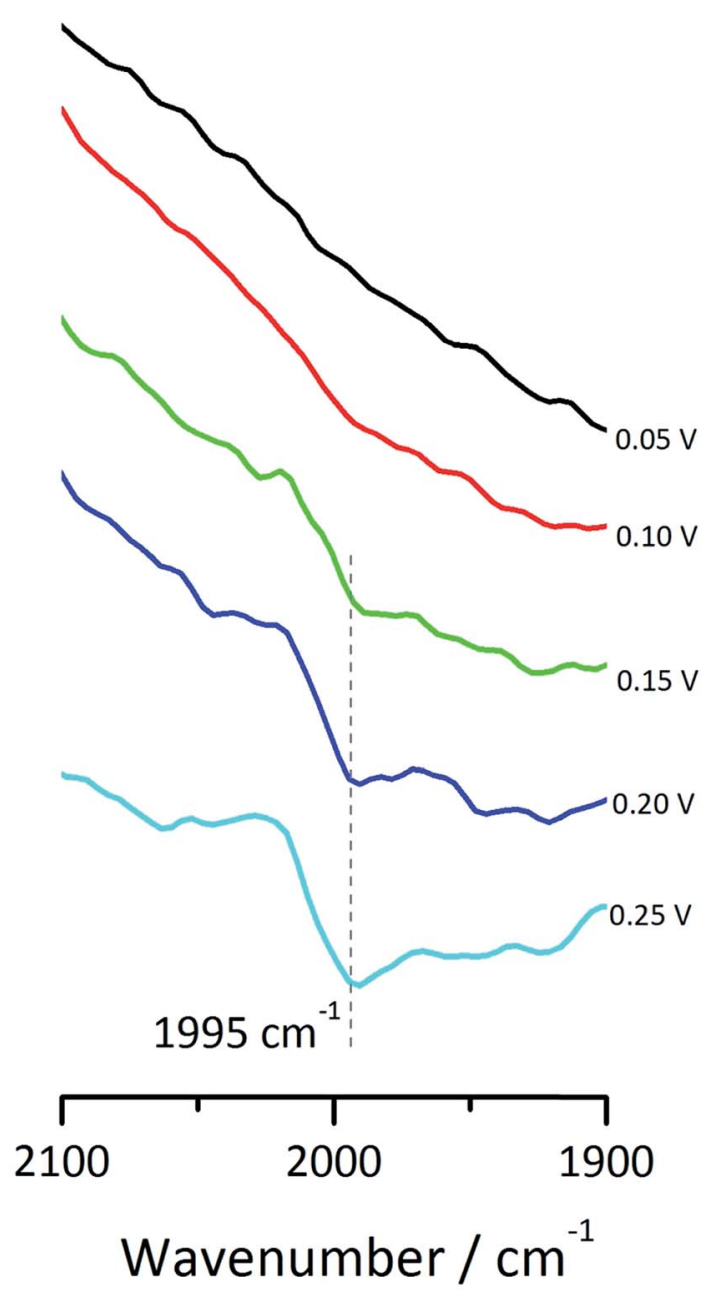

Fig. 9 FTIR spectra of a $\mathrm{Pt}(110)$ electrode in $0.1 \mathrm{M} \mathrm{H}_{2} \mathrm{SO}_{4}$ at the various indicated applied potentials after cathodization at $-0.2 \mathrm{~V}$ for 2 minutes.

\section{Discussion}

The surface chemistry corresponding to the peaks in the hydrogen region of a platinum electrode is highly sensitive to its nanoscale structure. On (111) terrace sites, protons are discharged to form adsorbed $\mathrm{H}_{\text {ads }}$ :

$$
\mathrm{H}^{+}+\mathrm{e}^{-} \leftrightarrows \mathrm{H}_{\mathrm{ads}}
$$


However, on step sites in a nanostructured or polycrystalline platinum surface, the reaction corresponding to peaks $\mathrm{H}_{\mathrm{I}}$ and $\mathrm{H}_{\mathrm{II}}$ is more accurately represented by:

$$
x \mathrm{OH}_{\text {ads }} \text {-cation }+(1+x) \mathrm{H}^{+}+(1+x) \mathrm{e}^{-}+\leftrightarrows \mathrm{H}_{\text {ads }}+x \mathrm{H}_{2} \mathrm{O}+x \text { cation }
$$

where $x$ is the (fractional) number of $\mathrm{OH}$ adsorbates replacing $\mathrm{H}_{\text {ads }}$, and the $\mathrm{OH}$ adsorbate is co-adsorbed with an alkali cation from the electrolyte (we implied 1 cation per $\mathrm{OH}$ in eqn (3) but this stoichiometry may not be accurate). The cation destabilizes the $\mathrm{OH}_{\text {ads }}$ in the step site by competing for neighboring water molecules. ${ }^{19,20}$ Reaction (3) applies to both (110) and (100) step sites. Reactions (2) and (3) are fast and reversible (in acidic media).

Some of the (110) sites can apparently be "reconstructed" by either an anodic $(>0.8 \mathrm{~V})$ or mild cathodic treatment $(-0.2$ to $-0.4 \mathrm{~V})$ to generate a new peak in the voltammogram: the third hydrogen $\mathrm{H}_{\mathrm{III}}$ peak. The reaction of the species involved in the $\mathrm{H}_{\text {III }}$ peak is slow and irreversible. The site of the species is stable in its reduced form, but unstable in its oxidized form. Two different interpretations exist in the literature as to the nature (of the hydrogen) of this peak. Various authors have suggested the formation of subsurface or occluded hydrogen., ${ }^{\mathbf{9}, 11,13}$ On the other hand, Gomez and Clavilier concluded that $\mathrm{H}_{\mathrm{III}}$ is formed at high hydrogen coverage on platinum electrodes with a sufficiently high density of (110) steps, and proposed a surface reconstruction of two-dimensional $(110)-(2 \times 1)$ domains, explaining why the $\mathrm{H}_{\text {III }}$ peak comes at the expense of the "regular" (110) step sites. Our FTIR experiments indeed show evidence for a surface-adsorbed $\mathrm{H}$ adsorbate oxidized in the $\mathrm{H}_{\text {III }}$ peak (Fig. 9), and do not lend support to the formation of a subsurface hydrogen species. While the $\mathrm{pH}$ dependence of peak $\mathrm{H}_{\mathrm{III}}$ in the limited 1-3 $\mathrm{pH}$ range suggests a $1 \mathrm{H}^{+} / 1 \mathrm{e}^{-}$reaction in the absence of cations (Fig. 8a), the effect of cations on the $\mathrm{H}_{\text {III }}$ peak appears to be different from that on the $\mathrm{H}_{\mathrm{I}}$ (and $\mathrm{H}_{\mathrm{II}}$ ) peak (Fig. 8b). One explanation for this could be that no $\mathrm{OH}_{\mathrm{ads}}$ is formed when $\mathrm{H}_{\mathrm{III}}$ is oxidized, and hence no interaction with cations is involved. However, one should keep in mind that as $\mathrm{H}_{\mathrm{III}}$ is oxidized, the local surface structure changes (Fig. 5 and 6b), and take into account that the charge corresponding to the $\mathrm{H}_{\mathrm{III}}$ is always larger than the corresponding loss in charge in $\mathrm{H}_{\mathrm{I}} \cdot{ }^{11,12}$ This may have an as yet not fully understood effect on the involvement of the co-adsorption of cations with $\mathrm{OH}_{\mathrm{ads}}$.

\section{Conclusion}

Our current understanding of the "hydrogen region" on nanostructured platinum electrodes suggests that it is not literally a hydrogen region. The various hydrogen peaks in the hydrogen region correspond to the replacement of adsorbed hydrogen by adsorbed hydroxyl. The latter species interacts with co-adsorbed cations through a competition for nearby water molecules, making the structure of the hydrogen region sensitive to cations. ${ }^{19}$ In this paper, we presented new data on an additional peak in the hydrogen region, traditionally called the "third hydrogen peak". Our experiments show the involvement of an top-adsorbed surface hydrogen species (as observed by FTIR), supporting the previous conclusion by Gomez and Clavilier ${ }^{12}$ that the third hydrogen peak is a surface peak, and not a subsurface hydrogen peak as suggested by various other authors. Specifically, the third hydrogen peak appears to involve a local reconstruction of 
two-dimensional $(2 \times 1)$ domains on a surface with a sufficiently high density of (110) steps. Such sites may be generated by extensive surface roughening, or by applying a high local hydrogen $\mathrm{H}_{2}$ concentration. The need for a high hydrogen coverage to stabilize the peak would explain its kinetic irreversibility as well as the rapid disappearance of the corresponding adsorption site once the corresponding hydrogen adsorbate is oxidized. The sensitivity of the third hydrogen peak to cations appears to be different from the other hydrogen peaks, which may be due to the unusual state of the corresponding surface site.

\section{Conflicts of interest}

There are no conflicts to declare.

\section{Acknowledgements}

We are grateful to Professor Juan Feliu (University of Alicante) for many useful discussions and suggestions. This work was partially supported by the European Union under the a-leaf project (732840-A-LEAF). We also acknowledge the partial support by Hitachi, Ltd. and Hitachi High-Technologies Corporation.

\section{References}

1 M. T. M. Koper, Nanoscale, 2011, 3, 2054.

2 V. Climent and J. M. Feliu, J. Solid State Electrochem., 2011, 15, 1297.

3 J. Solla-Gullon, P. Rodriguez, E. Herrero, A. Aldaz and J. M. Feliu, Phys. Chem. Chem. Phys., 2008, 10, 1359.

4 N. Tian, Z.-Y. Zhou and S.-G. Sun, J. Phys. Chem. C, 2008, 112, 19801.

5 S. E. F. Kleijn, S. C. S. Lai, M. T. M. Koper and P. R. Unwin, Angew. Chem., Int. Ed., 2014, 53, 3558.

6 D. Zhan, J. Velmurugan and M. Mirkin, J. Am. Chem. Soc., 2009, 131, 14756.

7 L. Jacobse, S. J. Raaijman and M. T. M. Koper, Phys. Chem. Chem. Phys., 2016, 18, 28451.

8 B. H. Loo and T. E. Furtak, Electrochim. Acta, 1980, 25, 505.

9 K. Kinoshita, J. Lundquist and P. Stonehart, J. Catal., 1973, 31, 325.

10 F. E. Woodward, C. L. Scortichini and C. N. Reilley, J. Electroanal. Chem., 1983, 151, 109.

11 M. P. Sumino and S. Shibata, Electrochim. Acta, 1992, 37, 2629.

12 R. Gomez and J. Clavilier, J. Electroanal. Chem., 1993, 354, 189.

13 T. Frelink, W. Visscher and J. A. R. van Veen, Electrochim. Acta, 1995, 40, 545.

14 M. E. Martins, C. F. Zinola and A. J. Arvia, J. Braz. Chem. Soc., 1997, 8, 363.

15 B. B. Berkes and G. Inzelt, J. Solid State Electrochem., 2014, 18, 1239.

16 J. Clavilier, D. Armand, S. Sun and M. Petit, J. Electroanal. Chem., 1986, 205, 267.

17 G. Garcia, P. Rodriguez, V. Rosca and M. T. M. Koper, Langmuir, 2009, 25, 13661.

18 M. J. T. C. van der Niet, N. Garcia-Araez, J. Hernandez, J. M. Feliu and M. T. M. Koper, Catal. Today, 2013, 202, 105.

19 X. Chen, I. T. McCrum, K. Schwarz, M. J. Janik and M. T. M. Koper, Angew. Chem., Int. Ed., 2017, 56, 15025. 
20 I. T. McCrum and M. J. Janik, ChemElectroChem, 2016, 3, 1609.

21 M. T. M. Koper, Electrochim. Acta, 2011, 56, 10645.

22 K. J. P. Schouten, M. J. T. C. van der Niet and M. T. M. Koper, Phys. Chem. Chem. Phys., 2010, 12, 15217.

23 G. A. Attard and A. Brew, J. Electroanal. Chem., 2015, 747, 123.

24 R. J. Nichols and A. Bewick, J. Electroanal. Chem., 1988, 243, 445.

25 K. Kunimatsu, T. Senzaki, G. Samjeské, M. Tsushima and M. Osawa, Electrochim. Acta, 2007, 52, 5715.

26 J. F. Li, Y. F. Huang, Y. Ding, Z. L. Yang, S. B. Li, X. S. Zhou, F. R. Fan, W. Zhang, Z. Y. Zhou, D. Y. Wu, B. Ren, Z. L. Wang and Z. Q. Tian, Nature, 2010, 464, 392.

27 H. Ogasawara and M. Ito, Chem. Phys. Lett., 1994, 221, 213.

28 M. J. Kolb, F. Calle-Vallejo, L. B. F. Juurlink and M. T. M. Koper, J. Chem. Phys., 2014, 140, 134708.

29 T. J. P. Hersbach, A. I. Yanson and M. T. M. Koper, Nat. Commun., 2016, 7, 12653.

30 L. Jacobse, Y. F. Huang, M. T. M. Koper and M. J. Rost, Nat. Mater., 2018, 17, 277. 